\title{
A large pharmacy claims-based descriptive analysis of patients with migraine and associated pharmacologic treatment patterns
}

This article was published in the following Dove Press journal:

Neuropsychiatric Disease and Treatment

10 November 201 I

Number of times this article has been viewed

\section{David J Muzina \\ William Chen \\ Steven J Bowlin}

Medco Health Solutions Inc and Medco Research Institute, LLC, Franklin Lakes, NJ, USA
Correspondence: David J Muzina I500I Trinity Blvd, \#300 Fort Worth, TX 76155, USA

$\mathrm{Tel}+\mathrm{I} 8173542184$

Fax +l 8173542162

Email david_muzina@medco.com
Purpose: To investigate drug use, prescribing patterns, and comorbidities among patients with migraine in a large pharmacy claims database.

Methods: 104,625 migraine subjects (identified according to the criteria in the International Classification of Diseases, Ninth Revision [ICD-9] for migraine or migraine-specific acute medication use) and an equal number of control patients were selected from a de-identified claims database; the prevalence of patients with migraine-specific claims was determined. Patient demographics, migraine-related medication use, other psychotropic medication use, and comorbidities over a 12-month period were compared between the migraine population and the control group and between migraine subgroups.

Results: Of the study population, 3.5\% had a migraine diagnosis according to the ICD-9 or received a migraine-specific acute medication. Compared with controls, migraine patients had significantly greater disease comorbidity and higher use of prescription nonsteroidal antiinflammatory drugs and controlled painkillers; they were also more likely to receive medications used to prevent migraines and other nonmigraine psychotropic medications, such as anxiolytics and hypnotics. Among migraine patients, $66 \%$ received acute migraine-specific medication while only $20 \%$ received US Food and Drug Administration-approved migraine preventive therapy. Notably, one-third of high triptan users did not receive any kind of preventive medication. Multiple medical and psychiatric comorbidities were observed at higher rates among migraine sufferers. In addition to significantly higher utilization of antidepressants compared with controls, migraine patients also received significantly more other psychotropic drugs by a factor of 2:1. Conclusion: Acute migraine medications are commonly used and frequently dispensed at rates that raise concern of overuse; high use is often seen without any preventive medications. Furthermore, use of US Food and Drug Administration-approved preventive medications is low. Finally, patients with migraine are significantly more likely to receive other psychotropic medications. These findings suggest efforts to optimize the management of migraines could address appropriate use of triptans, increased and more effective use of migraine preventive medications, and better understanding of the use of other psychotropics.

Keywords: headaches, triptans, migraine preventive therapy, comorbidity, psychotropics

\section{Introduction}

Migraine is a common and frequently chronic neurovascular condition with episodic exacerbations of varying intensity and frequency. In the USA, one in every four households includes a family member who suffers from migraine. ${ }^{1}$ The World Health Organization estimates that 324 million people have migraine, with prevalence rates among women two to three times greater than among men. ${ }^{2}$ Migraine is a major 
source of disability and lost working days for women aged 15-44 years in high-income countries, second only to unipolar depressive disorders. ${ }^{2}$ The frequency of migraine episodes ranges from daily headaches to less than a single migraine per month. Migraine management represents an important public health priority: in the insured US population alone, migraine-associated health care expenses amount to an estimated US\$11 billion in direct costs and almost US\$12 billion in indirect costs. ${ }^{3,4}$

Medication management of migraine may be classified into treatment of the acute headache phase and long-term migraine prevention. The introduction of the highly effective triptan class of medications for treatment of acute migraine has been followed by attempts in clinical practice to balance their efficacy with their unfavorable features: higher drug costs, potential drug interactions and adverse events, and symptomatic medication overuse with subsequent risk of clinical progression of the migraine condition from episodic to a chronic daily headache $(\mathrm{CDH})$.

Only four medications (divalproex sodium, propanolol, timolol, and topiramate) carry US Food and Drug Administration (FDA) indications as migraine preventive therapies. In addition to these approved preventive therapies, medications from several classes of drugs (including anticonvulsants, antidepressants, beta-blockers, and other antihypertensives) are frequently prescribed for migraine prophylaxis. Evidence-based approaches, such as the US Headache Consortium Guidelines, have been developed to describe circumstances warranting migraine preventive therapy. ${ }^{5}$ However, results of the American Migraine Prevalence and Prevention study suggest that, although $40 \%$ of migraine sufferers are eligible for migraine preventive therapies, only $13 \%$ receive such therapies. ${ }^{6}$

The present study investigates pharmacologic treatment patterns from 2008 to 2009 in insured patients with migraine using a large pharmacy and medical claims database. The aim was to study patients who received medical care for their migraines as evidenced by a medical diagnosis of migraine or use of migraine-specific acute medications (MSAMs). Prior research suggests that this subset of migraine patients has higher medical care utilization and costs than patients without claims evidence of migraine-related medical care. ${ }^{7}$ The primary objectives were to evaluate drug use patterns among migraine and control populations, focusing on triptans and other acute migraine medications, FDA-approved preventive therapies, commonly used "off-label" preventive medications, preventive medication use among high triptan users, and other psychotropic medications.

\section{Methods}

This study used a large de-identified medical and pharmacy claims database maintained by Medco Health Solutions Inc, Franklin Lakes, NJ, which contains more than 36 months of pharmacy and medical claims for over 13 million lives covered by more than 450 health plans. Pharmacy data were obtained for all medication claims filed with patient health plans receiving services from Medco Health Solutions Inc through both retail and mail channels. Medical claims for inpatient, outpatient, emergency department and nursing home visits, as well as the occurrence of laboratory and diagnostic testing were also available from health plans. Information arising from health care paid for through Medicare or entirely out of pocket without filing a claim through the health plan was not included in this database.

Claims from 2008 to 2009 were analyzed for patients aged between 18 and 62 years as of January 1, 2008 to avoid incomplete medical claims due to dual coverage by Medicare. Patients were required to have made at least one medical and one pharmacy claim during 2008. Patients with a medical claim for migraine and/or pharmacy claim codes for MSAMs filed between January 1, 2008 and December 31, 2008 were included in the migraine study cohort (Appendix 1). The control population was randomly selected from those patients aged 18-62 years without any migraine-specific claims during 2008-2009 in a 1:1 ratio to the migraine cohort. Control subjects were not matched to migraine patients for gender, age, or other variables. All subjects were followed and their prescription patterns and medical use tracked during a 12-month follow-up period that started as of the date of their first migraine-specific claim in 2008 (for the migraine cohort) or a randomly generated date in 2008 (for the control group). Patients not continuously eligible for payor-funded health care during the 12-month follow-up period were excluded from the migraine cohort and the control group.

To describe prescription patterns during the follow-up period, use of preventive medications (including FDA-approved and nonapproved classes), acute medications (including triptans and ergots), any migraine medications (acute or preventive), nonsteroidal anti-inflammatory drugs (NSAIDs), controlled painkillers (oral forms), and major classes of psychotropic medications not routinely used for migraine treatment (Appendix 2) were identified. Use of these medications was defined as the presence of one or more claims for the medication during the 12-month follow-up period. The total days of supply patients received for triptans, all acute medications, NSAIDs, and controlled 
painkillers was calculated. High triptan use was defined a priori as dispensing of triptan pills, sprays, or injections at a level that suggested the patient was treating more than 24 headaches during any 90-day rolling period. For this calculation, it was assumed that a quantity of two pills or injections (regardless of strength or specific triptan), two sprays of nasal sumatriptan, one subcutaneous injection of zolmitriptan, or one spray of nasal zolmitriptan was used for each headache. For each patient, the specialty of the prescriber of the first claim for psychotropic medications and MSAMs was identified.

International Classification of Diseases, Ninth Revision (ICD-9) codes associated with all medical claims for each patient during the follow-up period were evaluated to identify key comorbid conditions, defined a priori based on potential comorbidities of interest and reports in the literature (Appendix 3). ${ }^{8}$ Chronic disease score (CDS) was calculated from pharmacy claims data by methods similar to the original CDS developed by Von Korff and colleagues. ${ }^{9}$

Patient demographics, medication use, prescriber specialty, and comorbidities were compared between the migraine and the control groups. Migraine patients were stratified based on the types of migraine medications they received during the follow-up period (acute medications only, acute and preventive medications, preventive medications only, no migraine medications) and the characteristics of those who did not receive any migraine medications were compared with the three other medication treatment groups. Continuous variables were compared using the unpaired $t$-test. Categorical variables were compared using the chisquare test. All analyses were performed with SAS (v 9.1; SAS Institute Inc, Cary, NC) software.

\section{Results}

\section{Migraine patients compared with controls}

The authors identified 158,426 patients in the database with a migraine ICD-9 diagnosis and/or MSAM claim, which represented a $3.5 \%$ migraine prevalence rate among all patients with at least one medical and one medication claim during 2008 (Table 1). Of these patients, 104,625 met study criteria as migraine subjects after filters were applied for continuous eligibility during the follow-up period, age range restrictions, and presence of recorded gender. The control group consisted of 104,625 randomly selected patients without migraine. These groups, along with the four subgroups of migraine patients based on migraine treatment, are shown in Table 2.
Table I Migraine population from a national pharmacy and medical claims database with migraine prevalence calculation

\begin{tabular}{ll}
\hline Applied criteria & Number of patients \\
\hline $\begin{array}{l}\text { At least one medical and one medication } \\
\text { claim during 2008 }\end{array}$ & $4,542,788$ \\
$\begin{array}{l}\text { Presence of acute migraine medication } \\
\text { claim and/or migraine ICD-9 diagnosis }\end{array}$ & 158,426 \\
$\begin{array}{l}\text { Continuously eligible during follow-up period* } \\
\text { Gender not missing and age }=18-62 \text { years as }\end{array}$ & 124,339 \\
$\begin{array}{l}\text { of January I, 2008: migraine study cohort } \\
\text { Calculated prevalence of migraine patients } \\
(n=158,426)^{*}\end{array}$ & $3.5 \%$ \\
\hline
\end{tabular}

Note: *Follow-up period for the study was defined by the 12 months immediately following the start date of first migraine-specific claim in 2008 (migraine cohort) or a randomly generated date in 2008 (control group); this insured that all study subjects had a minimum of 12-months' continuous data available for analysis.

Abbreviation: ICD-9, International Classification of Diseases, Ninth Revision. ${ }^{8}$

The mean age of migraine subjects was 44 years and $83 \%$ were women. Compared with the control population, the migraine group had higher mean CDS, a higher percentage of patients with NSAID and controlled analgesic medication use, and received a significantly greater days' supply of these pain medications. Migraine sufferers were significantly more likely to have ICD-9 diagnoses for eight of the ten comorbid conditions studied than the control population - only diabetes and hypertension were observed at higher rates in the control population.

More than half (58\%) of the migraine group received pharmacotherapy that could be used for migraine prevention, though only one in five received medication approved by the FDA for migraine prophylaxis: $15 \%$ received an FDAapproved preventive anticonvulsant and 5\% received an FDAapproved preventive beta-blocker antihypertensive (Table 3 ). Half of the migraine group received pharmacotherapy that could be considered an off-label migraine preventive: $39 \%, 15 \%, 11 \%$, and $1 \%$ of all migraine subjects received antidepressants, other antihypertensives, other anticonvulsants, and/or other agents, respectively. In the control population, the use of any migraine preventive medication for any reason was significantly lower (33\%, rounded), with only about $1 \%$ (rounded) receiving an FDA-approved migraine preventive medication and 33\% (rounded) receiving drugs that are potential migraine preventive medications. Antidepressants were used less frequently in control compared with migraine patients (18\% versus 39\%, respectively).

Compared with the controls, the migraine group had significantly higher rates of use for other psychotropic drugs (excluding antidepressants, topiramate, and divalproex), with $30 \%$ receiving an anxiolytic, a new generation hypnotic, 
Table 2 Study characteristics of migraine and control subjects

\begin{tabular}{|c|c|c|c|c|c|c|}
\hline & \multirow{3}{*}{$\begin{array}{l}\text { Control group } \\
\text { (no migraine) }\end{array}$} & \multicolumn{5}{|c|}{ Migraine patients } \\
\hline & & \multirow[t]{2}{*}{ All migraine } & \multicolumn{4}{|c|}{ Migraine treatment status } \\
\hline & & & None & Acute only & $\begin{array}{l}\text { Acute and } \\
\text { preventive }\end{array}$ & $\begin{array}{l}\text { Preventive } \\
\text { only }\end{array}$ \\
\hline N (\%) & 104,625 & 104,625 & $15,847(15 \%)$ & $28,626(27 \%)$ & $40,855(39 \%)$ & $19,297(18 \%)$ \\
\hline Female & $57 \%$ & $83 \%^{\dagger}$ & $77 \%$ & $82 \% *$ & $87 \% *$ & $81 \% *$ \\
\hline Age (years) & $44.5(12)$ & $43.8(\mathrm{II})^{\dagger}$ & $40.6(12)$ & $43.1(1 \mathrm{I})^{*}$ & $45.4(\mathrm{II})^{*}$ & $44.5(\mathrm{II})^{*}$ \\
\hline CDS & $11(16)$ & $23(21)^{\dagger}$ & $7(13)$ & $17(14)^{*}$ & $33(23)^{*}$ & $22(22)^{*}$ \\
\hline NSAID use & $15 \%$ & $24 \%^{\dagger}$ & $20 \%$ & $19 \% €$ & $28 \% *$ & $27 \% *$ \\
\hline Days & $7(31)$ & $13(4 \mid)^{\dagger}$ & $7(26)$ & $8(30)^{*}$ & $17(50)^{*}$ & $14(42)^{*}$ \\
\hline Controlled pain med use & $25 \%$ & $47 \%^{\dagger}$ & $36 \%$ & $38 \% *$ & $56 \% *$ & $53 \% *$ \\
\hline Days & $8(38)$ & $27(70)^{\dagger}$ & $12(47)$ & II $(4 I)^{\epsilon}$ & $37(80)^{*}$ & $4 \mathrm{I}(87)^{*}$ \\
\hline Any psychotropic & $14 \%$ & $30 \%^{\dagger}$ & $15 \%$ & $17 \% *$ & $40 \% *$ & $39 \% *$ \\
\hline New gen hypnotics & $6 \%$ & $13 \%^{\dagger}$ & $5 \%$ & $8 \% *$ & $19 \% *$ & $16 \% *$ \\
\hline Anxiolytics & $9 \%$ & $20 \%^{\dagger}$ & $10 \%$ & $10 \%$ & $27 \% *$ & $28 \% *$ \\
\hline Antipsychotics & $0.9 \%$ & $3 \%^{\dagger}$ & $0.4 \%$ & $0.3 \%$ & $4 \% *$ & $4 \% *$ \\
\hline Mood stabilizer & $0.2 \%$ & $0.5 \%^{\dagger}$ & $0.1 \%$ & $0.1 \%$ & $0.9 \% *$ & $0.9 \% *$ \\
\hline Stimulants & $0.8 \%$ & $1.4 \%^{\dagger}$ & $0.7 \%$ & $0.6 \%$ & $2 \% *$ & $2 \% *$ \\
\hline \multicolumn{7}{|l|}{ Comorbidities } \\
\hline Depression & $7 \%$ & $16 \%^{\dagger}$ & $4 \%$ & $3 \% *$ & $24 \% *$ & $26 \% *$ \\
\hline Bipolar & $1 \%$ & $2 \%^{\dagger}$ & $0.5 \%$ & $0.3 \% *$ & $3 \% *$ & $4 \% *$ \\
\hline Anxiety & $6 \%$ & $12 \%^{\dagger}$ & $6 \%$ & $4 \% *$ & $16 \% *$ & $19 \% *$ \\
\hline Chronic pain & $0.6 \%$ & $2 \%^{\dagger}$ & $1 \%$ & $0.5 \% *$ & $3 \% *$ & $4 \% *$ \\
\hline Arthritis & $10 \%$ & $14 \%^{\dagger}$ & $11 \%$ & $9 \% *$ & $18 \% *$ & $20 \% *$ \\
\hline Fibromyalgia & $4 \%$ & $10 \%^{\dagger}$ & $7 \%$ & $5 \% *$ & $12 \% *$ & $13 \% *$ \\
\hline Sinusitis & $14 \%$ & $24 \%^{\dagger}$ & $22 \%$ & $20 \%^{*}$ & $26 \% *$ & $26 \% *$ \\
\hline Hypertension & $24 \%$ & $21 \%^{\dagger}$ & $13 \%$ & $9 \% *$ & $26 \% *$ & $36 \% *$ \\
\hline Diabetes & $9 \%$ & $5 \%^{\dagger}$ & $4 \%$ & $2 \% *$ & $6 \% *$ & $10 \% *$ \\
\hline Epilepsy & $0.8 \%$ & $2 \%^{\dagger}$ & $1 \%$ & $0.5 \% *$ & $3 \% *$ & $5 \% *$ \\
\hline
\end{tabular}

Notes: All values for age, CDS, days of NSAID and days of pain medication are reported as mean and standard deviation (SD). Days refer to the total days supplied of each type of medication over the 12-month observation period. Pain medications include oral Drug Enforcement Administration (DEA)-controlled painkillers; any psychotropics are based on >I claim for any psychotropic medication in each class during the 12-month observation period (see Appendix 2 for listing of study drugs). Comorbidities were determined by presence of ICD-9 codes during the I2-month observation period (see Appendix 3). Comparisons were made between (I) all migraine group and control group, and (2) each migraine treatment group and no migraine treatment group. ${ }^{t} P$ value $<0.0001$ compared with control group; $* P$ value $<0.000 \mathrm{I}$ compared with no migraine treatment group; $¥ P$ value $<0.001$ compared with no migraine treatment group; ${ }^{*}$ value $<0.01$ compared with no migraine treatment group; ${ }^{\epsilon} P$ value $<0.05$ compared with no migraine treatment group.

Abbreviations: CDS, chronic disease score; NSAID, non-steroidal anti-inflammatory drugs; ICD-9, International Classification of Diseases, Ninth Revision. ${ }^{8}$

an antipsychotic, a mood stabilizer and/or a stimulant drug (Table 2). Among patients receiving psychotropic medications, migraine patients were more likely than controls to have their psychotropic medication prescribed by a neurologist ( $7 \%$ versus $2 \%$, respectively; data not shown).

\section{Comparison of migraine treatment groups}

Fifteen percent of migraine patients did not receive any MSAM or preventive medication therapy, $18 \%$ received only migraine preventive therapy (either FDA-approved or other potential preventive medication), $27 \%$ received only acute migraine medications, and 39\% received acute and preventive medications (Table 2). The nontreated group was younger and had a lower percentage of women compared with the other three groups.
Prescribing of NSAIDs and controlled painkillers was similar in the untreated group and the group dispensed acute migraine medications only; both groups received less of these medications than those in the acute and preventive or preventive medications-only groups. The prevalence of controlled painkiller use among the migraine patients who received preventive medications was above $50 \%$.

Compared with patients receiving acute medication only, a greater percentage of the untreated migraine sample had comorbidities (Table 2); compared with patients receiving acute and preventive medications and preventive medications only, the untreated group had lower proportions with comorbidities. A lower percentage of migraine patients in the untreated and acute medication groups used psychotropics (excluding antidepressants) than in the two groups that received preventive medication. Across all four groups, more 
Table 3 Preventive medication (med) use in migraine and control patients

\begin{tabular}{|c|c|c|c|c|}
\hline & $\begin{array}{l}\text { Control patients, } \\
n=104,625\end{array}$ & $\begin{array}{l}\text { All migraine patients, } \\
n=104,625\end{array}$ & $\begin{array}{l}\text { Acute and preventive, } \\
\mathrm{n}=40,855(68 \%)\end{array}$ & $\begin{array}{l}\text { Preventive only, } \\
19,297(32 \%)\end{array}$ \\
\hline Any preventive med, $\mathrm{n} \%$ & $34,968(33 \%)$ & $60,152(58 \%)^{*}$ & - & - \\
\hline FDA-approved preventive & $1 \%$ & $20 \% *$ & $36 \%$ & $31 \%$ \\
\hline Anticonvulsant & $0.7 \%$ & $15 \% *$ & $28 \%$ & $24 \%$ \\
\hline Topiramate & $0.4 \%$ & $14 \% *$ & $25 \%$ & $21 \%$ \\
\hline Semisodium valproate & $0.4 \%$ & $2 \% *$ & $4 \%$ & $4 \%$ \\
\hline B-blocker & $0.6 \%$ & $5 \% *$ & $10 \%$ & $8 \%$ \\
\hline Propanolol & $0.6 \%$ & $5 \% *$ & $10 \%$ & $8 \%$ \\
\hline Timolol & $0 \%$ & $0.07 \% *$ & $0.1 \%$ & $0.1 \%$ \\
\hline Off-label preventive & $33 \%$ & $50 \% *$ & $87 \%$ & $88 \%$ \\
\hline Antidepressants & $18 \%$ & $39 \% *$ & $70 \%$ & $64 \%$ \\
\hline SSRI & $12 \%$ & $23 \% *$ & $40 \%$ & $37 \%$ \\
\hline SNRI & $3 \%$ & $10 \% *$ & $18 \%$ & $16 \%$ \\
\hline TCA & $1 \%$ & $8 \% *$ & $14 \%$ & $12 \%$ \\
\hline MAOI & $0.02 \%$ & $0.05 \% *$ & $0.1 \%$ & $0.1 \%$ \\
\hline Others & $5 \%$ & $11 \% *$ & $20 \%$ & $18 \%$ \\
\hline Antihypertensives & $17 \%$ & $15 \% *$ & $23 \%$ & $30 \%$ \\
\hline Alpha 2 agonists & $0.1 \%$ & $0.2 \% *$ & $0.3 \%$ & $0.5 \%$ \\
\hline $\mathrm{ACEI}$ & $12 \%$ & $8 \% *$ & $12 \%$ & $17 \%$ \\
\hline Beta-blockers (non-FDA) & $5 \%$ & $6 \% *$ & $9 \%$ & $12 \%$ \\
\hline Calcium channel blockers & $4 \%$ & $3 \% *$ & $4 \%$ & $7 \%$ \\
\hline Combinations without diuretic & $0.4 \%$ & $0.3 \% *$ & $0.3 \%$ & $0.7 \%$ \\
\hline Other Anticonvulsants & $4 \%$ & $11 \% *$ & $18 \%$ & $20 \%$ \\
\hline Others & $0.4 \%$ & $1 \% *$ & $2 \%$ & $3 \%$ \\
\hline
\end{tabular}

Note: $* P$ value $<0.000$ I comparing values for all migraine patients with control patients.

Abbreviations: SSRI, selective serotonin reuptake inhibitor; SNRI, serotonin-norepinephrine reuptake inhibitor; TCA, tricyclic antidepressant; MAOI, monoamine oxidase inhibitor; ACEI, angiotensin-converting enzyme inhibitors.

than half of the patients who received a psychotropic drug were initially prescribed the drug by a primary care provider (data not shown).

Among migraine subjects, two-thirds received acute treatment at some point during the study period and $60 \%$ received triptans (Table 4). Sixteen percent (rounded) of all migraine patients and $26 \%$ of triptan users $(16,526$ and 62,639 patients, respectively) received triptans in amounts suggesting the acute treatment of more than 24 headaches in a 90 day period (defined as high triptan users). Among the
16,526 migraine patients identified as high triptan users, $33 \%$ $(5,415 / 16,526)$ did not receive any migraine preventive drug during the study period.

\section{Discussion \\ Prevalence, characteristics, and comorbidity}

The 3.5\%, 1-year period prevalence of migraine in this large US pharmacy claims database is, as expected, lower than the $\sim 13 \%$ prevalence reported from recent US cross-sectional

Table 4 Acute migraine-specific medication use

\begin{tabular}{|c|c|c|c|}
\hline & $\begin{array}{l}\text { All migraine patients, } \\
\mathrm{n}=104,625\end{array}$ & $\begin{array}{l}\text { Acute medication only, } \\
\mathrm{n}=28,626\end{array}$ & $\begin{array}{l}\text { Acute and preventive medication, } \\
n=40,855\end{array}$ \\
\hline Any acute medication & $69,48 \mathrm{I}(66 \%)^{\dagger}$ & $28,626(27 \% *)^{*}$ & $40,855(39 \% *)$ \\
\hline Days of supply, mean (SD) & $59(84)$ & $76(82)^{*}$ & $98(94)$ \\
\hline Any triptan use & $62,639(60 \% €)$ & $25,795(90 \% €)$ & $36,844(90 \% €)$ \\
\hline Days of supply, mean (SD) & $57(84)$ & $74(83)^{*}$ & $94(95)$ \\
\hline High triptan use $\mathrm{e}^{\ddagger}$ & $16,526(16 \% €)$ & $5,4 \mid 5(19 \% €)^{*}$ & $|I| I \mid,(27 \% €)$ \\
\hline
\end{tabular}

Notes: ${ }^{\dagger}$ Values are $\mathrm{n}(\%)$ unless otherwise specified; thigh triptan use was defined as the dispensing of triptans that treated more than 24 headaches during any 90 -day rolling period. Two pills or injections (regardless of strength or specific triptan), 2 sprays of nasal sumatriptan, I subcutaneous injection of zolmitriptan, or I spray of nasal zolmitriptan was defined as the amount of drug used for one headache; ${ }^{*}$ proportion of all migraine patients; ${ }^{\epsilon}$ proportion of column total; ${ }^{*} P$ value $<0.000 \mathrm{I}$ comparing values for acute medication only versus acute and preventive medication groups.

Abbreviation: SD, standard deviation. 
survey studies. ${ }^{10}$ This lower prevalence is partly because only half of migraine sufferers receive care from a physician and less than half use prescription medications. ${ }^{10}$ Others have shown that migraine patients who have an ICD-9 diagnosis or receive MSAMs use more health care resources and probably have more severe disease than those identified by interview criteria alone. ${ }^{8,11,12}$ The migraine patients identified in this study were most likely to be those with the greatest migraine-related morbidity.

Consistent with other studies, the present analysis found a striking female preponderance among migraine sufferers, with a female to male ratio of $4.9: 1 .^{8,11}$ Migraine patients had significantly higher CDS scores than the control population, indicating greater aggregate comorbidity. Originally validated for use as a predictor of physician-rated disease status, self-rated health status, hospitalization, and mortality, ${ }^{9}$ the observed difference in CDS scores confirms previous observations of greater clinical complexity and overall poorer health status among migraine sufferers. Migraine patients had significantly higher rates of epilepsy, psychiatric disorders (such as anxiety, bipolar spectrum disorder, and depression) and painful conditions (such as chronic pain, fibromyalgia, arthritis and sinusitis). In addition, compared with the control group, migraine patients had significantly higher use of other analgesics - NSAIDs and US Drug Enforcement Administration-controlled painkillers. The use of opioids in patients with migraine is of particular concern due to the potential for development of tolerance, addiction, and dependence, as well as worsening of the primary headache disorder. ${ }^{12,13}$ There is also mounting evidence that opioid use in migraine may lead to medication-overuse headache, decreased responsiveness to other migraine medications, and poorer long-term outcomes. ${ }^{15-19}$

The finding in this study of increased prevalence of epilepsy among migraine patients compared with the control group ( $2 \%$ versus $0.8 \%$, respectively) is consistent with a prior study ( $5.9 \%$ versus $0.5 \%$, respectively) ${ }^{20}$ although the magnitude of difference was much lower in the present study. This is an important medical comorbidity to recognize among migraine sufferers since many of the psychotropic drugs (such as antidepressants and antipsychotics) used either as offlabel for migraine preventive therapy or to treat psychiatric comorbidity have the potential to lower seizure threshold. ${ }^{21}$ Some caution must be used, however, when interpreting comorbidity data from individuals seeking medical treatment for two separate conditions due to a potential Berkson's selection bias - such patients often demonstrate a high rate of association between two medical conditions that may be independent in the general population. ${ }^{22}$

This study found a lower prevalence of hypertension among migraine sufferers compared with the control group. Prior studies have demonstrated inconsistent associations between hypertension and migraine, although more recent studies suggest hypertension may be associated with chronic daily headache $(\mathrm{CDH})$ and a potential risk factor for chronification of migraine..$^{23,24}$

The potential association between migraine and diabetes has been poorly studied. Historically, authors of clinical observations and small studies have commented on the rarity of migraine among patients with diabetes mellitus, suggesting diabetes may offer some protection against migraine..$^{25,26}$ The present study found that patients with migraine in the Medco database were almost two times less likely to have diabetes than those in the control group. Whether glucose homeostasis plays a contributing role in the pathophysiology of migraine remains unknown and warrants further exploration.

\section{The use of migraine acute and preventive medications}

Only $20 \%$ of patients with migraine received an FDAapproved drug for migraine prevention. To the authors' knowledge, this is the first claims-based study to report on the prevalent use of FDA-approved migraine preventive therapies in a population of diagnosed and/or treated migraine patients. This finding supports earlier reports, such as the American Migraine Prevalence and Prevention study, which state that a minority of migraine patients receive FDA-approved preventive therapy. ${ }^{7,27}$ When broadening the definition of preventive medications to include any medication potentially used for migraine prevention, more than half of migraine patients received these medications. Most of the "off-label" migraine preventive drugs used in the present study were antidepressants and it was unable to be determined if their use was for migraine or for a psychiatric condition.

Lafata and colleagues also evaluated preventive medication use among patients with migraine and reported that only $13.4 \%$ of all migraine cases and $12.4 \%$ of control patients were users of migraine preventive medications. ${ }^{7}$ They studied patients from a single nonprofit health plan serving residents of southeast Michigan, used structured telephone interviews to characterize patients as migraine or control, and evaluated use of preventive medications using linked health insurer claims data. The higher prevalence of any preventive 
medication use among migraine and control patients in the present study may be explained by several factors:

- The current study focused on migraine patients who had received either a diagnosis of migraine and/or used MSAMs, rather than patients identified by phone interview, and were therefore more likely to receive preventive medication.

- Lafata et al required two claims for the same medication class to count as preventive medication use, while this study required only one.

- Control patients in the present study were required to have at least one prescription claim and therefore were more likely to receive commonly prescribed medications, such as antidepressants.

A significant proportion of migraine patients in the present study received treatment with either FDA-approved and/ or other potential migraine preventive $\operatorname{drug}(\mathrm{s})$, however, the authors' findings show that preventive medications are still underused in a sizable portion of patients with migraine.

Most concerning is the lack of preventive medication use in one of every three patients who received amounts of triptans suggesting a headache frequency of greater than 24 in a 90-day period. Patients who have more than two acute migraine attacks per month and/or whose daily activity is compromised by headaches are universally considered candidates for preventive medication. ${ }^{6,7}$ Therefore, a significant number of patients eligible for preventive therapy were either not prescribed or did not fill prescriptions for preventive medication during the study period. Further, in the migraine population in this study receiving only acute migraine medication, 19\% were high triptan users. This is of concern given the potential risk for medication-overuse headache or $\mathrm{CDH}$. Population studies show that about 3\% of patients with episodic migraine develop $\mathrm{CDH}$ over 1 year of follow-up. ${ }^{28} \mathrm{CDH}$ is linked to excessive acute migraine medication use, greater disability, and higher rates of medical comorbidity (including depression, anxiety, and fibromyalgia), as well as elevated suicide risk. ${ }^{19,29-33}$

Interestingly, migraine patients receiving preventive drugs used significantly greater amounts of NSAIDs and controlled painkillers compared with those not obtaining preventive medications. Prior studies have demonstrated reduction in triptan use in patients who start migraine preventive medications. ${ }^{34-37}$ This study found that migraine patients using both preventive and acute medications received more triptans and had a greater percentage of high triptan users than patients receiving acute medications alone. There are several possible explanations for these findings:
- channeling bias, where those who have worse migraine symptoms are also more likely to receive preventive medications

- the possibility that the preventive medications were started later in the follow-up year, after the high acute medication use

- the potential for residual migraine symptoms even with preventive medication use.

Nonadherence with preventive medications could also contribute to greater utilization of acute analgesic medications, including triptans.

\section{The "untreated" but diagnosed migraine population}

In this study, about one in six migraine patients did not receive any migraine-specific medication therapy. This "untreated" population was younger and had a lower percentage of women than the treated populations. Most notably, use of NSAIDs and controlled painkillers was common in the untreated migraine group and nearly of equal prevalence with use among those receiving only acute migraine-specific therapy. Untreated migraine patients had higher rates for all ten of the comorbid conditions explored compared with those receiving only acute migraine therapies but utilized less overall psychotropic pharmacotherapy (15\% versus $17 \%$ ). Together with prior research suggesting that triptans are started in only $5 \%$ of all migraine patients, these findings raise questions about whether there is therapeutic inertia against appropriate use of acute migraine medications in some patients and what factors might be influencing this pattern of care. ${ }^{38}$

\section{Psychiatric comorbidity}

This study found that patients with migraine were often diagnosed with comorbid depression, anxiety, bipolar spectrum disorders, and more often prescribed medications commonly used to treat insomnia, attention-deficit disorder, and psychosis. Additionally, nearly one in three migraine patients received psychotropic drugs (other than anticonvulsants or antidepressants) not routinely used for migraine treatment. These psychotropic drugs were used twice as frequently among migraine patients as in the control group (30\% versus 14\%, respectively). More than half of migraine patients who received any psychotropic drug had their psychotropic prescribed by a primary care provider.

Psychiatric comorbidity has been associated not only with an increased susceptibility to headaches but also with potential refractoriness to migraine drug therapy and 
chronification of migraine. ${ }^{39}$ Substance abuse, illicit drug use, and nicotine dependence have also been linked to migraine. ${ }^{13}$ Despite the recognition of a bidirectional association between migraine and psychiatric disorders, this linkage has been frequently clinically discussed but seldom systematically studied. Future studies are needed to better understand the migraine to mental health connection and optimal treatment setting and approach for patients with both migraine and psychiatric comorbidities.

\section{Study limitations}

This claims-based study had limitations that need to be understood in interpreting the data. As in all claims-based analyses, the data were not collected for research but for administrative billing purposes, which might lead to misclassification of migraine and comorbidity diagnoses. Selected drug prescribing for 12 months after an ICD-9 migraine diagnosis that appeared in the authors' claims history was assessed; this permitted examination of the subsequent 12-month-period prevalence of co-medication use. Whether the co-medications were prescribed to specifically treat the patients' migraine or other conditions (eg, depression or anxiety) is not known. However, in comparing the migraine patients with the control group, it is clear that the prevalent use of most of the co-medications was higher in the migraine patients. The study sample in this study included ICD-9diagnosed patients and/or those receiving MSAMs; patients with undiagnosed migraine or those who did not seek physician care for their headaches were not included. Further, the sample was biased toward patients who sought care, who most likely had more severe headaches, more comorbidity, and more co-medications than individuals who did not seek care; however, this study provides valuable information for the segment of the US migraine population seeking care for their migraine disorder.

\section{Conclusion}

This study supports existing perspectives on migraine as a complex disorder with significant variability in drug treatment patterns and medical and psychiatric comorbidities. The active utilization of migraine preventive medications is relatively low, particularly for FDA-approved drugs. Nearly one-third of patients who used high levels of triptans did not receive any preventive therapy. Despite preventive therapy, many patients were high triptan users and utilized other analgesics, such as NSAIDs and controlled painkillers. Comorbidity was common; especially interesting was the authors' observations of associations between migraine and various psychiatric conditions and their treatments. The majority of migraine patients receive their acute medications and other psychotropic medications from primary care physicians rather than neurologists or psychiatrists. Additional research is needed to better understand patterns of resource use by patients with migraine and the potential role of other health care professionals, such as pharmacists, to help promote evidence-based migraine care and improve patient outcomes. Given their visibility to and knowledge of prescription histories for patients, pharmacists have the opportunity to play a key role in identifying those patients with migraine for whom preventive medication may be indicated and beneficial, particularly for those patients demonstrating a pattern of triptan or other acute analgesic overuse.

\section{Acknowledgments}

All authors are employees of Medco Health Solutions Inc or its affiliates. The authors thank Cindy Fenton, MD (Department of Medicine, Division of Hospital Medicine, University of California, San Francisco; Strategic Health Partners), and Steve Haffner, MD, consultants to Medco Health Solutions Inc, for their review of study design and an earlier version of the manuscript.

\section{Disclosure}

The authors report no conflicts of interest in this work.

\section{References}

1. National Headache Foundation. Categories of Headache. Available from: http://www.headaches.org/press/NHF_Press_Kits/Press_ Kits_-_Categories_of_Headache. Accessed July 14, 2010.

2. The global burden of disease: 2004 update. Geneva: World Health Organization, 2008. Available from: http://www.who.int/healthinfo/ global_burden_disease/GBD_report_2004update_full.pdf. Accessed July $14,2010$.

3. Hawkins K, Wang S, Rupnow M. Direct cost burden among insured US employees with migraine. Headache. 2008;48(4):553-563.

4. Hawkins K, Wang S, Rupnow M. Indirect cost burden of migraine in the Unites States. J Occup Environ Med. 2007;49(4):368-374.

5. Silberstein SD; for the US Headache Consortium. Practice parameter: Evidence-based guidelines for migraine headache. Report of the Quality Standards Subcommittee of the American Academy of Neurology. Neurology. 2000;55(6):754-762.

6. Lipton RB, Bigal ME, Diamond M, et al. Migraine prevalence, disease burden, and the need for preventive therapy. Neurology. 2007;68(5): 343-349.

7. Lafata JE, Moon C, Leotta C, Kolodner K, Poisson L, Lipton RB. The medical care utilization and costs associated with migraine headache. J Gen Intern Med. 2004;19(10):1005-1012.

8. National Center for Health Statistics. International Classification of Diseases, Ninth Revision. Atlanta, GA: CDC/National Center for Health Statistics; 2009.

9. Von Korff M, Wagner EH, Saunders K. A chronic disease score from automated pharmacy data. J Clin Epidemiol. 1992;45(2):197-203. 
10. Lipton RB, Scher AI, Kolodner K, Liberman J, Steiner TJ, Stewart WF. Migraine in the United States: Epidemiology and patterns of health care use. Neurology. 2002;58(6):885-894.

11. Lipton RB, Diamond S, Reed M, Diamond ML, Stewart WF. Migraine diagnosis and treatment: results from the American Migraine Study II. Headache. 2001;41(7):638-645

12. Lipton RB, Stewart WF, Diamond S, Diamond ML, Reed ML. Prevalence and burden of migraine in the United States: data from the American Migraine Study II. Headache. 2001;41:646-657.

13. Breslau N, Davis GC. Migraine, physical health and psychiatric disorder: A prospective epidemiologic study in young adults. $J$ Psychiatr Res. 1993;27(2):211-221.

14. Tepper SJ, Tepper DE. Breaking the cycle of medication overuse headache. Cleveland Clinic Journal of Medicine. 2010;77(4):236-242.

15. Ho TW, Rodgers A, Bigal ME. Impact of recent prior opioid use on rizatriptan efficacy. A post hoc pooled analysis. Headache. 2009; 49(3):395-403.

16. Wilkinson SM, Becker WJ, Heine JA. Opiate use to control bowel motility may induce chronic daily headache in patients with migraine. Headache. 2001;41(3):303-309.

17. Bahra A, Walsh M, Menon S, Goadsby PJ. Does chronic daily headache arise de novo in association with regular use of analgesics? Headache. 2003;43(3):179-190.

18. Bigal ME, Serrano D, Buse D, Scher AI, Stewart WF, Lipton RB Acute migraine medications and evolution from episodic to chronic migraine: a longitudinal population-based study. Headache. 2008; 48(8):1157-1168.

19. Bigal ME, Lipton RB. Excessive acute migraine medication use and migraine progression. Neurology. 2008;71(22):1821-1828.

20. Andermann E, Andermann F. Migraine-epilepsy relationships: epidemiological and genetic aspects. In: Andermann F, Lugaresi E, editors. Migraine and Epilepsy. Boston, MA: Butterworth-Heinemann; 1987:281-291

21. Haddad PM, Dursun SM. Neurological complications of psychiatric drugs. Hum Psychopharmacol. 2008;23 Suppl 1:15-26.

22. Walter SD. Berkson's bias and its control in epidemiologic studies. J Chronic Dis. 1980;33(11-12):721-725.

23. Agostoni E, Aliprandi A. Migraine and hypertension. Neurological Sciences. 2008;29 Suppl 1:37-39.

24. Barbanti P, Aurilia C, Egeo G, Fofi L. Hypertension as a risk factor for migraine chronification. Neurol Sci. 2010;31 Suppl 1:41-43.

25. Burn WK, Machin D, Waters WE. Prevalence of migraine in patients with diabetes. Br Med J (Clin Res Ed). 1984;289(6458):1579-1580.
26. Dandona P, James IM, Beckett AG. Prevalence of migraine in patients with diabetes. Br Med J (Clin Res Ed). 1985;290(6466):467-468.

27. Diamond S, Bigal ME, Silberstein S, Loder E, Reed M, Lipton RB. Patterns of diagnosis and acute and preventive treatment for migraine in the United States: results from the American Migraine Prevalence and Prevention study. Headache. 2007;47(3):355-363.

28. Scher AI, Stewart WF, Ricci JA, Lipton RB. Factors associated with the onset and remission of chronic daily headache in a population-based study. Pain. 2003;106(1-2):81-89.

29. Bigal ME, Rapoport AM, Lipton RB, Tepper SJ, Sheftell FD. Assessment of migraine disability using the migraine disability assessment (MIDAS) questionnaire: a comparison of chronic migraine with episodic migraine. Headache. 2003;43(4):336-342.

30. Dodick DW. Clinical practice. Chronic daily headache. $N$ Engl J Med. 2006;354(2):158-165.

31. Verri AP, Proietti Cecchini A, Galli C, Granella F, Sandrini G, Nappi G. Psychiatric comorbidity in chronic daily headache. Cephalalgia. 1998; 18 Suppl 21:45-49.

32. Peres MF, Young WB, Kaup AO, Zukerman E, Silberstein SD. Fibromyalgia is common in patients with transformed migraine. Neurology. 2001;57(7):1326-1328.

33. Pompili M, Serafini G, Di Cosimo D, et al. Psychiatric comorbidity and suicide risk in patients with chronic migraine. Neuropsychiatr Dis Treat. 2010;6:81-91.

34. Silberstein SD, Winner PK, Chmiel JJ. Migraine preventive medication reduces resource utilization. Headache. 2003;43(3):171-178.

35. Mei D, Ferraro D, Zelano G, et al. Topiramate and triptans revert chronic migraine with medication overuse to episodic migraine. Clin Neuropharmacol. 2006;29(5):269-275.

36. Feliu AL, Rupnow MF, Blount A, Boccuzzi SJ, Vermilyea J. Resource use associated with topiramate in migraine prophylaxis. Am J Health Syst Pharm. 2007;64(14):1483-1491.

37. Silberstein SD, Feliu AL, Rupnow MF, Blount AC, Boccuzzi SJ. Topiramate in migraine prophylaxis: long-term impact on resource utilization and cost. Headache. 2007;47(4):500-510.

38. Bigal ME, Buse DC, Chen YT, et al. Rates and predictors of starting a triptan: results from the American Migraine Prevalence and Prevention Study. Headache. 2010; 50(9):1440-1448.

39. Pietrini P, Guazzelli M. Life events in the course of chronic diseases: A psychological myth or a psycho-neuro-biochemical loop? Clin Exp Rheumatol. 1997;15(2):125-128. 


\section{Appendices}

Appendix I Markers used to identify migraine patients from pharmacy and medical claims

\begin{tabular}{ll}
\hline Medical claim with ICD-9 code for migraine or related phenomenon during 2008 & $346 *, 784,339 *$ \\
Pharmacy claim for migraine-specific acute medication & $\begin{array}{l}\text { Any triptan } \\
\text { Any ergotamine }\end{array}$ \\
\hline
\end{tabular}

Notes: ICD-9 code descriptors: 346* (migraine), 784 (headache), 339* (other headache syndromes, eg, complicated headache syndrome); *denotes code extensions 0.00 through 0.99 , inclusive.

Abbreviation: ICD-9, International Classification of Diseases, Ninth Revision. ${ }^{8}$

Appendix 2 Classification of drug markers

\begin{tabular}{|c|c|c|c|c|}
\hline $\begin{array}{l}\text { Acute migraine } \\
\text { medications }\end{array}$ & $\begin{array}{l}\text { Preventive migraine } \\
\text { medications }\end{array}$ & $\begin{array}{l}\text { Psychotropic } \\
\text { drugs }\end{array}$ & $\begin{array}{l}\text { Controlled } \\
\text { painkillers* }\end{array}$ & $\begin{array}{l}\text { Prescription } \\
\text { NSAIDs** }\end{array}$ \\
\hline Ergotamines & US FDA approved & New generation hypnotics & Opioids & Mefenamic acid \\
\hline Triptans & Divalproex & Anxiolytics & $+l-$ APAP & Indomethacin \\
\hline Almotriptan & Propanolol & Benzodiazepines & $+/-$ caffeine & Ibuprofen \\
\hline Eletriptan & Timolol & Buspirone & $+/-$ NSAID & Fenoprofen \\
\hline Frovatriptan & Topiramate & Antipsychotics & Butalbitals & Tolmetin \\
\hline Naratriptan & Other potential preventives & Atypical antipsychotics & $+/-\mathrm{ASA} /$ caffeine & Naproxen \\
\hline Rizatriptan & Antidepressants & Typical antipsychotics & $+/-$ APAP/caffeine & Flurbiprofen \\
\hline Sumatriptan & Antihypertensives & Mood Stabilizer (lithium) & +/- codeine & Sulindac \\
\hline \multirow[t]{8}{*}{ Zolmitriptan } & Anticonvulsants & Stimulants & Isometheptene & Meclofenamate \\
\hline & Miscellaneous & Amphetamines & Butorphanol NS & Piroxicam \\
\hline & Baclofen & Atomoxetine & & Diclofenac \\
\hline & Cyproheptadine & Modafinil & & Ketoprofen \\
\hline & & & & Ketorolac \\
\hline & & & & Etodolac \\
\hline & & & & Nabumetone \\
\hline & & & & Oxaprozin \\
\hline
\end{tabular}

Notes: *Only oral forms of these painkillers were used as drug markers with the exception of butorphanol nasal spray (NS); **only prescribed NSAIDs were used as drug markers, over-the-counter NSAIDs not part of the database.

Abbreviations: ASA, acetylsalicylic acid; APAP, acetaminophen; NSAIDs, nonsteroidal anti-inflammatory drugs; US FDA, US Food and Drug Administration.

Appendix 3 Other comorbid diagnostic conditions identified in the study population

\begin{tabular}{|c|c|}
\hline Diagnostic condition clusters & ICD-9 codes used \\
\hline Depression (unipolar) & $296.2^{*}, 296.3^{*}, 300.4$, and 311 \\
\hline Anxiety disorders & $293.84,300.0^{*}, 300.2 *, 300.3$, and 309.81 \\
\hline Bipolar spectrum disorders & $296.0^{*}, 296 . I^{*}, 296.4^{*}, 296.5^{*}, 296.6^{*}, 296.7,296.80,296.89$, and 301.13 \\
\hline Chronic pain & $307.8,307.80,338,338.0,338.2,338.29$, and 338.4 \\
\hline Arthritis & $274^{*}, 7|4.0,7| 4 .|, 7| 4.2,7|4.3,7| 4.30,7|4.3|, 7|4.33,7| 4.4,7|4.89,7| 4.9,7\left|5^{*}, 7\right| 6^{*}, 720.0$, and $72 I^{*}$ \\
\hline Fibromyalgia & $728.87,728.89$, and 729.1 \\
\hline Sinusitis & $461 *$ and $473 *$ \\
\hline Hypertension & $401 *, 402^{*}, 403^{*}, 404^{*}, 405^{*}, 642^{*}$, and 997.91 \\
\hline Diabetes & $249 *, 250^{*}, 362.0,366.41$, and $648.0^{*}$ \\
\hline Epilepsy & $345^{*}, 780.39$, and $649.4^{*}$ \\
\hline
\end{tabular}

Note: *Any numerical code extensions of the root code number.

Abbreviation: ICD-9, International Classification of Diseases, Ninth Revision. ${ }^{8}$

Neuropsychiatric Disease and Treatment

\section{Publish your work in this journal}

Neuropsychiatric Disease and Treatment is an international, peerreviewed journal of clinical therapeutics and pharmacology focusing on concise rapid reporting of clinical or pre-clinical studies on a range of neuropsychiatric and neurological disorders. This journal is indexed on PubMed Central, the 'PsycINFO' database and CAS. The manuscript

\section{Dovepress}

management system is completely online and includes a very quick and fair peer-review system, which is all easy to use. Visit http://www. dovepress.com/testimonials.php to read real quotes from published authors. 